\title{
THE USE OF PROVERBS IN THE TEACHING OF ARABIC
}

\author{
ERNEST MCCARUS \\ University of Michigan
}

A major trend in all phases of language training today is toward the integration of linguistic training with cultural orientation. 1 This is true of college instruction, where the ideal language course is considered by many to be an introduction to a foreign culture through the acquisition of a linguistic competence, as well as in elementary schools, where possibly the most important objective of language training is "dispelling in the youngster a fear or suspicion of the foreign, the unfamiliar and the unknown, introducing him to a foreign people and their culture."2 A device which the author has found remarkably successful in combining contextual orientation with linguistic training in the teaching of colloquial Arabic is the use of proverbs. 3

Proverbs seem to be well-established in most, if not all, of the major cultures of the world; there is readily available in many libraries a considerable number of works on proverbs, ranging from studies on individual proverbs to relatively complete collections of sayings found in particular languages. 4 These provide an excellent source of ready-made

${ }^{1}$ See, for example, Chapter V, "Contextual Orientation," in Charles C. Fries, Teaching and Learning English as a Foreign Language (Ann Arbor, 1945), pp. 57-61.

2 Otto Graf, "German Instruction on Fourth Grade Level," Language Learning, V, (1955), p. 84.

${ }^{3}$ The term proverb is used here in a broad sense to include not only popular maxims but also common sayings from literature and scripture, as the Bible or the Koran. Even clichés, as "the straight and narrow," can be included here.

4For example, for Arabic see Charles A. Ferguson and John $M$. Echols, "Critical Bibliography of Spoken Arabic Proverb Literature," Journal of American Folklore, LXV, Mo. 255 (1952), 67-84.

For some critical bibliographies on proverbs in all languages, see-Archer Taylor, "An Introductory Bibliography for the Study of Proverbs," Modern Philology, XXX (1933), 195-210.

Richard Jente, "A Review of Proverb Literature Since 1920," Corona. Studies in Celebration of the Eightieth Birthday of Samuel Singer (Durham, N.C., 1941), pp. 23-41. 


\section{THE USE OF PROVERBS}

linguistic texts for use in classroom instruction. Further, as their correct usage requires some explanation of cultural differences, they guarantee a certain amount of contextual orientation for the learner. In the following discussion of this two-fold usefulness of proverbs as instructional material, the author will draw on his experience as a teacher of colloquial Arabic as well as his experience, and that of other researchers, 5 in the Near East itself. Although, the observations made in this paper refer most directly to colloquial Arabic and to the Arabic-speaking communities of Lebanon and Syria, still, they are merely specific applications of general principles which should be applicable to most language learning situations.

The Arabic-speaking peoples have a tremendous store of proverbs; what is more, they are extremely fond of them, and proverbs have a definite place in their daily life. They often have poetic or other literary value, or they may sum up the wisdom and philosophy of the people. They can be mordant or humorous, but they are always expressive and effective. Accordingly, researchers in the field have found that proverbs provide an excellent entrée into a new community. If the newcomer has taken the trouble to learn their values before visiting them, the local people will welcome him more readily. Knowledge of their proverbs shows interest in them, and ties the outsider to them and their traditions. In a social situation, a proverb will often "break the ice"-when one person leads off with a proverb, others usually follow in rapid succession. One field worker had only to begin a proverb and the local inhabitants would quickly finish it.

As proverbs often have literary value or are associated with wisdom or even religion, certain prestige accrues to those who have mastered them. Speeches and other formal styles of expression are often embellished with proverbs and maxims. Many proverbs in common use are in. Classical Arabic (a literary language quite different from colloquial Arabic), as / Parsaltuhu liya xaațiban fatazawwaž/ "I sent him to her to propose [for me] and he married [her]." In this connection, proverbs can give an impression of fluency to a foreigner's speech. Since a proverb is concentrated in meaning, it is equivalent to several sentences or paragraphs of grammatically and stylistically perfect Arabic.

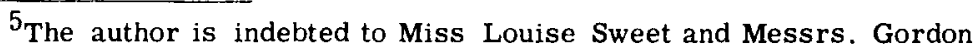
Torrey and James Young for their kindness in describing to him their experiences with proverbs in their field work in northern Syria. 


\section{LANGUAGE LEARNING}

Proverbs are useful not only in relating to people but even in inducing certain reactions from them. Without going into the psychology of language, it does seem that behavior can be influenced to a certain degree by appealing to stereotyped traditions and beliefs. Perhaps the following incident will illustrate this best:

A social scientist was doing field work in a Muslim village in the mountains of Lebanon, when a local malcontent began to hamper his work seriously by means of a whispering campaign directed against him. The trouble-maker was thoroughly discredited and his damage undone when, at a gathering of the elders of the village, the researcher merely quoted a familiar saying from the Koran which identifies whisperers with Satan: $/ ?_{a} c_{u u z u}$ birabb innaas min šarr ilwaswaas ilxannaas/ "I seek refuge in the Lord of mankind, From the evil of the sneaking whisperer." 6

As proverbs cover all phases of culture, they are often a convenient didactic device. A Syrian lawyer explaining local legal structure in Arabic to an American would regularly illustrate points of law with proverbs, so that his explanations were always clear. For example, in explaining that the Syrian Constitution gives the courts the power to pass sentences but does not give them the power to enforce their sentences, the lawyer summed up the situation with the saying /llisaan saayil wil?iid marbuuta/ "The tongue is free but the hand is tied."

An anthropologist doing a village study in Syria found many proverbs on weather and agriculture in common use. She had trouble with the multiplicity of calendars in use, until she learned a number of common sayings which helped her keep calendaric dates in order. She reports, too, that a father would often use proverbs to explain right and wrong to his son-for example, to illustrate why the son was punished for a certain deed. Some of the etiquette sayings are/ddiHk balaa sabab min ?illt l?adab/ "Laughter without cause is from insufficiency of upbringing" and /Habl lkizb ?așiir/ "The rope of lying is short." These correspond to our clichés, as "It serves him right," or the British "It isn't done."

Proverbs can be a clue to attitudes. In a certain village, the people would usually not register their emotions on their faces. They would, however, often express their inner feelings by proverbs, as /šaayib u dalluu caayib/ "He has

6Translation from Mohammed Marmaduke Pickthall, The Meaning of the Glorious Koran (New York, 1953), p. 455. 
gray hair and he's still shameful [in conduct]" to show disapproval of a person's behavior.

Perhaps a word of caution should be inserted here: proverbs are not descriptions of actual behavior, but are idealizations of how a people would like their behavior to be. While proverbs may be used to illustrate points in the description of the structure of a particular society, merely a collection of proverbs alone is not sufficient basis for an accurate characterization of a given community.

Finally, in the case of a language which shows a great deal of dialectal variations, 7 proverbs, which tend to be current over large speech areas, provide a series of controlled texts for isolating the phonemic, lexical, and morphological contrasts between dialects with little effort. A student who had studied the Lebanese Arabic of Beirut was doing field work in a rural community in northern Syria. A proverb given in the Beiruti dialect would immediately be repeated by the local people in their own Beduin-type dialect; the dialectal readjustments to be made were thus clearly exposed to the researcher. To give an example of this, the Beiruti proverb / ?iza kaan lkalaam min fidda sskuut min dahab/ "If speech is of silver then silence is of gold" is / Pida čaan lkalaam min fidfda sskuut min dahab/ in the Beduin dialect. The following correspondences in consonants occur:

Beiruti: Beduin:

$\begin{array}{ll}/ \mathrm{z} / & / d / \\ / \mathrm{d} / & / d / \\ / \mathrm{d} / & / d / \\ / \mathrm{k} / & / \mathrm{k} / \\ / \mathrm{k} / & / \mathrm{c} /\end{array}$

Investigation of further data shows the following correspondences as well:

Beiruti:

$\begin{array}{ll}/ z / & / z / \\ / d / & / d /\end{array}$

${ }^{7}$ In Lebanon, for example, each village has its own typical dialect, and in cities each quarter has its own dialect. There is further fragmentation based on religion, social class, etc.; however, all Lebanese dialects are mutually intelligible. 


\section{LANGUAGE LEARNING}

If each correspondence is symbolized by a letter preceded by $(*)$, they can be arranged as follows:

$\begin{array}{lrrrr}\text { Correspondence: } & /{ }^{*} \mathrm{~d} / & / *^{+} / & / *_{\mathbf{z}} / & /{ }^{*} \mathrm{k} / \\ \text { Beiruti: } & / \mathrm{d} / & / \mathrm{d} ; \mathrm{z} / & / \mathrm{z} / & / \mathrm{k} / \\ \text { Beduin: } & / \mathrm{d} / & / \mathrm{d} / & / \mathbf{z} / & / \mathrm{k} ; \mathrm{c} /\end{array}$

Thus, Beduin has in this group of consonants two which are lacking in Beiruti. It can be stated that $/ d /$ and $/ z /$ of Beduin always correspond to $/ \mathrm{d} /$ and $/ \mathrm{z} /$ of Beiruti; however, some instances of Beiruti / $/$ / correspond to Beduin $/ d /$ and others to Beduin $/ \mathcal{J} /$; a parallel situation obtains for Beiruti $/ z /$. Correspondence $/ * j /$ is not predictable as to whether Beiruti will show $a / d /$ or $a / z /$. In the case of the correspondence $/ * \mathrm{k} /$, it is Beduin which has two consonants to one of Beiruti. Further research would show that /c/ developed from $/ \mathrm{k} /$ through palatalization before front vowels. While $/ \mathbf{k} /$ and $/ \check{c} /$ seem now to be separate phonemes in this dialect, the ability to remember more easily if not predict the occurrence of $/ \check{c} /$ rather than $/ \mathrm{k} /$ in many instances is certainly a useful aid.

As the differences between related dialects are regular and are statable in terms of generalizations, learning a new dialect is considerably facilitated by observing these differences as was done using the proverb above. 8

Thus, proverbs can be useful in establishing rapport with a group, relating to or influencing them, and may be quite efficacious for didactic purposes. They are a valuable aid not only in the field, however, but in the classroom as well. They are useful in the teaching and learning of pronunciation, vocabulary, and grammar.

In order to master the pronunciation of a foreign language, it is essential to be able to hear and reproduce the phonemic contrasts of that language. One is much more likely to encounter a contrast in a phrase than in a word cited out of context. For example, in Lebanese Arabic if a given word has one velarized consonant then the entire word tends to

${ }^{8}$ For some comparisons between Syrian Arabic proverbs and Iraqi Arabic proverbs, see Dayton S. Mak, "Some Syrian Arabic Proverbs," Journal of the American Orienlal Society, LXIX (1949), 223-282, and Arthur B. Allen, "Some Iraqi Proverbs and Proverbial Phrases," Journal of the American Orienlal Society, LXXV (1955), 122-125. 


\section{THE USE OF PROVERBS}

become velarized. 9 Consequently, the occurrence of both velarized $/ d /$ and non-velarized $/ d /$, for example, will be encountered more readily in a phrase than in a single word. In /zkoor ddiib $u$ hayyii 1 ?adiib/ "Mention the wolf and prepare the stick" (like our "Speaking of the Devil, here comes..."), /diib/ "wolf" and / Padiib/ "stick" provide a nearly minimal pair in which the difference between the two $/ d / ' s$ is strikingly clear.

Some English-speaking students find that the more difficult consonants in Arabic are controlled more easily in proverbs. Furthermore, juncture phenomena, elisions, special intonational patterns, etc., may be more easily practiced and retained in such formulaic or semi-formulaic phrases. In the proverb above, for example, the syllabification of /zkoor/ "mention" and /ddiib/ "the wolf" in context is /zkoo rid diib/-that is, the vowel /i/ regularly occurs between the first and second consonants of a three-consonant cluster in utterance-medial position (with certain exceptions).

If $\mathrm{C}$ is made to stand for any consonant, this can be stated by the formula $\mathrm{C}+\mathrm{CC}>\mathrm{CiCC}$. This phenomenon strikes the student as soon as he hears words pronounced in phrases or larger utterances; if he learns the proverb correctly he will be that much closer to making this regular process of Arabic a part of his new set of speech habits.

It is even more important in the case of vocabulary items to learn words in context. A well-known FrenchEnglish dictionary gives the following English equivalents for foule: "Crowd, throng, multitude, concourse; mob, rabble, common herd; fulling. "10 How is the foreigner to choose the word with the proper connotation in order to avoid being misunderstood or even offending his audience? One effective way to face this problem is to learn not only words but phrases, sentences, and even stories; proverbs are one special type of text that is easily available to teacher and learner. In / ?illi baytuu min ?zaaz maa biyraaši? biliHžaar/ "He whose house is made of glass does not hurl stones" /biyraaši?/ means "hurls, pelts"; it occurs almost always with /Hžaar / "stones, rocks" and implies "at people." If $/ \mathrm{rmii} /$, the usual Lebanese word for "to throw," were used

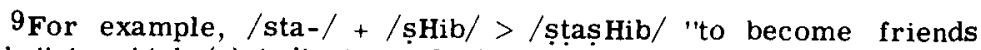
with," in which (.) indicates velarization.

10 Cassell's New French-English English-lirench Dictionary, ed. Ernest A. Baker (New York, 1930), p. 289. 


\section{LANGUAGE LEARNING}

in this proverb, the meaning would be not so much "hurl stones at people" as "throw stones (down)," which is hardly the intended effect here. Learning these nuances of meaning will help the student acquire a "feeling" for the language.

As for motivation, a proverb which cleverly makes its point, like the proverb/liHmaar $b^{c}$ ayn ?immuu gazaal/ "The donkey in the eyes of his mother is a gazelle," is more challenging and easier to fix in one's memory than such meaningless sentences as "Ahmad has six cows" or "Juan saw the brown bear," with which so many learners are plagued in the early stages of language study.

When it comes to morphology and syntax, it is easier to remember a proverb than a grammatical rule. By using the usual substitution techniques with the proverb as the frame, proverbs can play a vital rôle in the oral method of language instruction. A simple illustration of a proverb used to drill the imperative forms of the verb (masculine singular, femi-. nine singular, and common plural) follows. The proverb /naam bakkiir u ?uum bakkiir u šuuf șșiHHa kiif bițșiị/ means "Sleep early and arise early and see your health how it will become." /naam/, /?uum/ and /suuf/are imperative forms of the verb for /?inta/ "you" (masculine singular). The verb shows special forms also for the other two pronouns in the second person, /?intii/ "you" (feminine singular) and /?intuu/ "you" (common plural). The teacher calls on the individual students of the class in turn, requiring them to modify the entire sentence according to the pronoun supplied, as

Model: /naam bakkiir $u$ ?uum bakkiir $u$ šuuf șșiHHa kiif bițsiiṛ/

Teacher: /?intii/

Student: /naamii bakkiir u ?uumii bakkiir u šuufii șșiHHa kiif bițsiir/

Teacher: /?intuu/

Student: /naamuu bakkiir u ?uumuu bakkiir u šuufuu șșiHHa kiif bițșiir/

In this drill, the verbs /naam/, / ?uum/, and /šuuf/ of the model sentence were changed to /naamii/, / ?uumiil, and /šufii/ respectively to correspond to the pronoun/?intii/ and were changed to /naamuu/, /?uumuu/, and /šuufuu/ respectively for / Pintuu/.

The use of pronouns obviates the cumbersome use of terms as "second person masculine singular" and, further, 


\section{THE USE OF PROVERBS}

facilitates the conducting of the drill entirely in Arabic. As the conjugation of the verb in the present tense is based on the /?inta/ form of the imperative, the drill can be carried a step further to practice the present tense forms, again using the pronouns, as

Teacher: / 'ana/ ' $\mathrm{I}$ '

Student: /bnaam bakkiir u b?uum bakkiir u bšuuf șșiHHa kiif etc. biț̣iir/

Another way to drill the forms of the present tense using this same proverb is to leave everything constant except /ssiHHa/ "the health," which is feminine singular. By varying this word, substituting in its place other nouns, as / raasak/ "your head" (masculine singular noun) or /druusak/ "your lessons" (plural noun), the verb / bitșiir/ "she becomes" must be changed accordingly, as, referring to the last part of the proverb, /...u suuf șșiHHa kiif biț̣iị̂/ we get

Teacher: / raasak/

Student: /...u šuuf raasak kiif biyṣiị̂/ "... and see how your head will be"

Teacher: /druusak/

Student: /...u šuuf druusak kiif biyṣiiruu / "... and see how your lessons will be"

The pattern practice technique suggested here can be developed in many ways, and is widely accepted today as an effective drill technique.

Perhaps one of the strangest features of Arabic syntax to English speakers is the fact that there is no equivalent expressed in Arabic for the English words "am," "are," "is." Thus, $/ 1^{\mathrm{c}}$ atabii tultayn ddarb/, equivalent to our "Well begun is half done," is, literally, "the threshold two-thirds the way," i.e., "the threshold is two-thirds of the way." /tultayn ddarb/ "two thirds [of] the way" is another special syntactic construction of two nouns expressing usually a genitive relationship. The proverb / Pillii baytuu min ?zaaz maa biyraaši? biliHžaaṛ/ cited earlier also contains an Arabic construction not found in English. Literally, this proverb means "who his house from glass not pelts with stones." That is, Arabic has no word corresponding to English "whose"; English "he whose house is of glass" would be in Arabic "who 


\section{LANGUAGE LEARNING}

his house from glass." Thus, all the important differences between English and Arabic syntax can be illustrated by proverbs.

The advantages in language learning listed above are not the exclusive property of proverbs, but are to be had whenever phrases and texts larger than single words are the basic units of instruction. Proverbs are especially useful, however, because they are a readily available corpus of idiomatic texts which appeal to the imagination, are retained with comparatively little effort, and whose content has intrinsic value. It has also been shown that in actual contacts with native speakers, they can provide an entrée and are highly successful in relating to those peoples who esteem them. While the discussion here has been specifically in terms of Arabic speech areas, the same should be true in many other cultures as well. After all, as the Arabs say, /maa ?aal lmatal šii min lkizb/ "the proverb has never told a lie." 